\title{
Breast-feeding initiation and exclusive duration at 6 months by social class - results from the Millennium Cohort Study
}

\author{
YJ Kelly and RG Watt* \\ Department of Epidemiology and Public Health, University College London, 1-19 Torrington Place, \\ London WC1E 6BT, UK
}

Submitted 9 August 2004: Accepted 9 October 2004

\begin{abstract}
Objectives: To assess breast-feeding initiation and rates of exclusive breast-feeding for the first 6 months after birth, and to examine social class differences in breast-feeding rates.

Design: First sweep of a longitudinal population-based survey, the Millennium Cohort Study.

Setting: Four countries of the UK.

Subjects: Subjects were 18125 singletons born over a 12-month period spanning 2000-01. Data were collected by parental interview on the initiation of breast-feeding and exclusivity at 1, 4 and 6 months after birth.

Results: Overall breast-feeding was initiated for $71 \%$ of babies, and by 1,4 and 6 months of age the proportions being exclusively breast-fed were 34\%,3\% and $0.3 \%$, respectively. There were clear social class differences and mothers with routine jobs with the least favourable working conditions were more than four times less likely (odds ratio (OR) 0.22 , 95\% confidence interval (CI) $0.18-0.29$ ) to initiate breastfeeding compared with women in higher managerial and professional occupations. Women in routine jobs were less likely to exclusively breast-feed their infants at 1 month (OR 0.42, 95\% CI 0.36-0.50) and 4 months (OR 0.5, 95\% CI 0.31-0.77) compared with women in higher managerial and professional occupations.

Conclusions: Clear social class differences in breast-feeding initiation and exclusivity for the first 4 months were apparent in this large UK sample. By 6 months, less than 1\% of babies were being exclusively breast-fed. A co-ordinated multi-faceted strategy is required to promote breast-feeding, particularly among lower-income women.
\end{abstract}

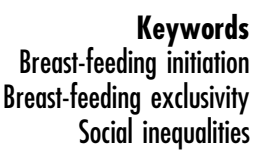

A wealth of scientific evidence has highlighted the benefits of breast-feeding for infants and mothers ${ }^{1-6}$. Recently, the UK Department of Health modified its breast-feeding recommendations and now advocates that wherever possible infants should be fed exclusively on breast milk from birth until 6 months of age. These recommendations are in support of the World Health Organization's infant feeding guidance ${ }^{7}$. The promotion of breast-feeding has been highlighted in a range of policy developments as a means of improving health, and in particular as a way of reducing health inequalities among mothers and children $^{8}$. The Department of Health recently set a target on breast-feeding for Primary Care Trusts to 'deliver an increase of two percentage points per year in breastfeeding initiation rates, focusing especially on women from disadvantaged groups 9 .

Despite the recognised benefits and the implementation of a range of initiatives to promote the initiation and duration of breast-feeding, rates in the UK remain low compared with many other parts of the world. The UK Infant Feeding 2000 survey reported initial breast-feeding rates at $70 \%$ in England and Wales, 63\% in Scotland and $54 \%$ in Northern Ireland ${ }^{10}$. By 6 months, $21 \%$ of babies in the total sample were still being fed breast milk. However, precise figures on exclusive breast-feeding were not collected in the survey. Since the previous Infant Feeding Survey in 1995 little change had occurred in breast-feeding rates in England and Wales, although significant increases took place in both Scotland and Northern Ireland. Marked inequalities are apparent in breast-feeding. Mothers most likely to initiate breast-feeding are those who reach higher educational levels, are in Social Class I or II, are aged over 30 years, and are feeding their first as opposed to subsequent babies ${ }^{10}$.

The Millennium Cohort Study (MCS) is a longitudinal survey of a large sample of babies born in 2000-01 across the UK. The first wave of data collection assessed a range of health and developmental outcomes in a sample of over 18000 infants $^{11}$. This dataset provides a valuable source of information from a large representative sample of UK children. The aim of the present paper was to assess breast-feeding initiation and rates of exclusive 
breast-feeding for the first 6 months, and to examine social class differences in breast-feeding rates.

\section{Methods}

The MCS sample was drawn from babies born in the UK during a 12-month period spanning the years 2000-2001. The survey design, recruitment process and fieldwork have been described in detail elsewhere ${ }^{11}$. Briefly, 18553 households agreed to participate in the survey. Households were identified through the Department of Work and Pensions Child Benefit system and were selected on the basis of where the family was resident just after the time of birth. The sample is clustered at the electoral ward level, and disadvantaged residential areas are overrepresented.

The survey involved home visits by interviewers when the cohort member was aged on average 9.2 (standard deviation (SD) 0.5) months. During the interview questions were asked about the socio-economic circumstances of the family and the health and well-being of the baby, including the initiation and duration of breast- and bottle-feeding. Rates of exclusive breast-feeding were determined by identifying babies whose carer reported that breast-feeding had been initiated and had not been given formula, cow's or any other sort of milk/fluid or solid foods at 1, 4 and 6 months of age.

\section{Data analysis}

Data were analysed for all singleton births $(n=18125)$. Breast-feeding initiation and exclusivity at 1,4 and 6 months were examined by social class of the mother by occupation (National Statistics Socio-Economic Classification (NS SEC) in seven categories: 1, Higher managerial and professional; 2, Lower managerial and professional; 3, Intermediate; 4, Small employees and self-employed; 5, Lower supervisory and technical; 6, Semi-routine; 7, Routine). This social class schema was first used in the 2001 census and is based on the following principles, which are markers of working conditions: timing of payment (monthly, weekly, daily or hourly); presence of incremental pay; job security; degree of autonomy; promotion opportunities; degree of planning own work tasks $^{12}$. Breast-feeding rates were also stratified by the following potential confounders: parity (first or subsequent child), sex of baby, mother's age in five bands $(<20,20-24,25-29,30-34, \geq 35$ years), smoking (nonsmoker, 0-9, 10-19, $\geq 20$ cigarettes per day), household income in equivilised quintiles of the distribution and family structure (one- or two-parent).

Logistic regression models were run with initiation of breast-feeding and exclusivity at 1, 4 and 6 months of age as the dependent variables. Independent variables were entered into the model in two stages: first, social class and second, sex of baby, parity and mother's age, cigarette smoking, family composition and income. Data were weighted to take account of the sampling framework, ensuring that the study sample was representative of the population of 9-month-old babies resident in the UK during the recruitment period. All analyses were performed using Stata version 8.2 (StataCorp, College Station, TX, USA).

\section{Results}

Table 1 shows the social and demographic characteristics of the sample. The mean age (SD) of the mothers interviewed was 29.7 (5.8) years and 36\% of the sample

Table 1 Social and demographic characteristics of the population sample

\begin{tabular}{|c|c|c|}
\hline & $n$ & $\%$ \\
\hline \multicolumn{3}{|l|}{ Sex of baby } \\
\hline Female & 8807 & 48.6 \\
\hline Male & 9317 & 51.4 \\
\hline Total & 18125 & \\
\hline \multicolumn{3}{|l|}{ Mother's age (years) } \\
\hline$<20$ & 1304 & 7.2 \\
\hline $20-24$ & 3019 & 16.7 \\
\hline $25-29$ & 4949 & 27.3 \\
\hline $30-34$ & 5700 & 31.5 \\
\hline$\geq 35$ & 3128 & 17.3 \\
\hline Total & 18101 & \\
\hline \multicolumn{3}{|l|}{ Parity } \\
\hline First child & 7736 & 42.7 \\
\hline Second or subsequent child & 10389 & 57.3 \\
\hline Total & 18125 & \\
\hline \multicolumn{3}{|c|}{ Number of cigarettes smoked by mother per day } \\
\hline Non-smoker & 12966 & 71.6 \\
\hline$<10$ & 2027 & 11.2 \\
\hline $10-19$ & 2211 & 12.2 \\
\hline$\geq 20$ & 910 & 5.0 \\
\hline Total & 18113 & \\
\hline \multicolumn{3}{|l|}{ Country of residence } \\
\hline England & 14829 & 81.8 \\
\hline Wales & 947 & 5.2 \\
\hline Scotland & 1720 & 9.5 \\
\hline Northern Ireland & 630 & 3.5 \\
\hline Total & 18125 & \\
\hline \multicolumn{3}{|l|}{ NS SEC by mother's occupation } \\
\hline Higher managerial and professional & 1307 & 7.8 \\
\hline Lower managerial and professional & 4272 & 25.6 \\
\hline Intermediate & 3287 & 19.7 \\
\hline Small employers and self-employed & 764 & 4.6 \\
\hline Lower supervisory and technical & 950 & 5.7 \\
\hline Semi-routine & 3688 & 22.1 \\
\hline Routine & 2403 & 14.4 \\
\hline Total & 16672 & \\
\hline \multicolumn{3}{|c|}{ Equivilised household income in quintiles of the distribution } \\
\hline Highest & 4178 & 24.9 \\
\hline Second highest & 3807 & 22.7 \\
\hline Middle & 2895 & 17.3 \\
\hline Second lowest & 2878 & 17.2 \\
\hline Lowest & 3021 & 18.0 \\
\hline Total & 16799 & \\
\hline \multicolumn{3}{|l|}{ Family structure } \\
\hline Two-parent & 15241 & 84.2 \\
\hline One-parent & 2858 & 15.8 \\
\hline Total & 18099 & \\
\hline
\end{tabular}

NS SEC - National Statistics Socio-Economic Classification. 
worked in semi-routine and routine occupations (NS SEC).

Figure 1 shows the proportion of babies for whom breast-feeding was initiated and the duration of exclusive breast-feeding by social class. Seventy-one per cent of the total sample was initially breast-fed. A clear social class gradient in breast-feeding initiation was evident. For example, 93\% of mothers from the higher managerial and professional occupational group initiated breast-feeding compared with $53 \%$ of mothers in routine occupations. A social gradient in breast-feeding initiation was apparent apart from those in the small employees and selfemployed group. At 1 week, 50\% of the sample was being exclusively breast-fed. By 1 month this had dropped to $34 \%$, and at 4 months $3 \%$ was exclusively breast-fed. By 6 months, only $0.3 \%$ of the sample was still being exclusively fed breast milk. Clear social class differences in exclusive breast-feeding were apparent over time.

Table 2 shows the proportion of babies for whom breast-feeding was initiated and was exclusive at 1, 4 and 6 months by social and demographic factors. Initiation and exclusive feeding rates were higher among mothers aged 30 or over, who were non-smokers, living in higherincome households, who lived with a partner and who were first-time mothers. Rates were highest in England and lowest in Northern Ireland.

Table 3 shows odds ratios (ORs) and 95\% confidence intervals (CIs) estimated using logistic regression analysis for the effect of occupational social class on the initiation and duration of exclusive breast-feeding. The adjusted figures reveal that women with routine occupations with the least favourable working conditions were over four times less likely to initiate breast-feeding than women with the most favourable working conditions in higher managerial and professional occupations. The adjusted OR for exclusive breast-feeding at 1 and 4 months was 0.42 and 0.50 , respectively. The rates of exclusive breast-feeding at 6 months were too low to undertake further analysis.

\section{Discussion}

The results from this study provide an up-to-date insight into the extent of breast-feeding initiation rates across a socially diverse, large UK sample of babies born at the beginning of the new millennium. Moreover, using data collected in the MCS allowed us to assess exclusive breastfeeding rates. Seventy-one per cent of the sample initiated breast-feeding. Exclusive rates of breast-feeding at 1 week following the birth were 50\%. By 1 month this had dropped to $34 \%$, and by 4 months only $3 \%$ of the sample was exclusively breast-fed. At 6 months, the recently recommended period for exclusive breast-feeding by the Department of Health, only $0.3 \%$ of the sampled mothers were still feeding their infant exclusively on breast milk.

There were clear social class differences in rates of breast-feeding, with mothers in occupations with the least favourable working conditions being more than four times less likely to initiate breast-feeding, and twice as likely not to exclusively breast-feed their babies at 1 and 4 months of age, compared with women working in occupations with the most favourable conditions.

Similar rates of breast-feeding initiation were reported in the most recent Infant Feeding Survey ${ }^{10}$, but in contrast to the Infant Feeding Survey the use of MCS data has allowed us to estimate the proportion of babies who were being exclusively breast-fed. A clear picture of exclusive breast-feeding rates is particularly useful in light of the recent Department of Health recommendations. By 4 months, only $3 \%$ of the babies were being exclusively breast-fed and by 6 months this had dropped to $0.3 \%$. Furthermore, in this paper we have moved beyond a purely descriptive analysis to assess the independent effect of social class on breast-feeding rates.

The MCS has collected high-quality data from a large, socially diverse UK sample and the NS SEC provides social class data based upon the mother's occupation. The NS

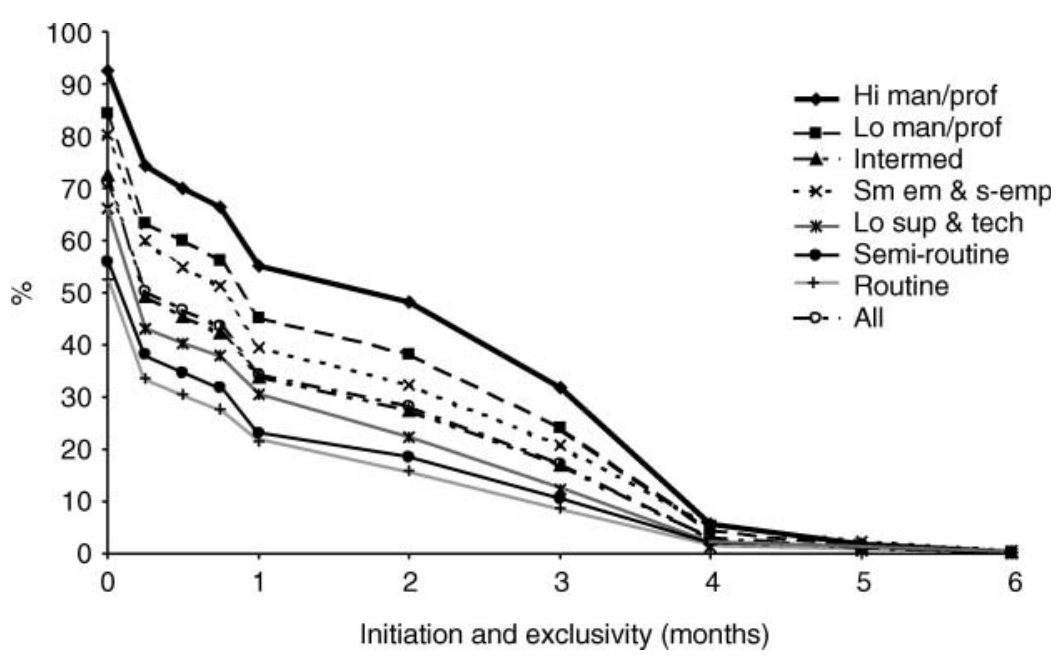

Fig. 1 Breast-feeding initiation and exclusivity by social class (National Statistics Socio-Economic Classification: Hi man/prof - Higher managerial and professional; Lo man/prof - Lower managerial and professional; Intermed - Intermediate; Sm em \& s-emp - Small employees and self-employed; Lo sup \& tech - Lower supervisory and technical; Semi-routine; Routine) 
Table 2 Breast-feeding initiation and exclusivity by social and demographic factors

\begin{tabular}{|c|c|c|c|c|c|c|c|c|}
\hline & \multicolumn{8}{|c|}{ Breast-feeding } \\
\hline & \multicolumn{2}{|c|}{ Initiated } & \multicolumn{2}{|c|}{$\begin{array}{l}\text { Exclusive } \\
\text { at } 1 \text { month }\end{array}$} & \multicolumn{2}{|c|}{$\begin{array}{l}\text { Exclusive } \\
\text { at } 4 \text { months }\end{array}$} & \multicolumn{2}{|c|}{$\begin{array}{l}\text { Exclusive } \\
\text { at } 6 \text { months }\end{array}$} \\
\hline & $\%$ & $n$ & $\%$ & $n$ & $\%$ & $n$ & $\%$ & $n$ \\
\hline \multicolumn{9}{|l|}{ Sex of baby } \\
\hline Female, $n=8800$ & 69.9 & 6151 & 34.0 & 2992 & 3.5 & 308 & 0.3 & 26 \\
\hline Male, $n=9306$ & 70.5 & 6561 & 32.7 & 3043 & 3.0 & 279 & 0.3 & 27 \\
\hline \multicolumn{9}{|l|}{ Mother's age (years) } \\
\hline$<20, n=1301$ & 45.7 & 594 & 12.6 & 164 & 1.0 & 13 & 0.2 & 2 \\
\hline $20-24, n=3018$ & 58.0 & 1751 & 20.8 & 628 & 1.7 & 51 & 0.1 & 3 \\
\hline $25-29, n=4945$ & 69.9 & 3455 & 32.3 & 1595 & 3.0 & 146 & 0.3 & 13 \\
\hline $30-34, n=5697$ & 77.0 & 4383 & 39.1 & 2225 & 3.4 & 195 & 0.3 & 18 \\
\hline$\geq 35, n=3127$ & 80.5 & 2515 & 45.3 & 1417 & 5.7 & 177 & 0.5 & 16 \\
\hline \multicolumn{9}{|l|}{ Parity } \\
\hline First child, $n=7730$ & 75.0 & 5798 & 32.6 & 2520 & 2.5 & 193 & 0.2 & 12 \\
\hline Second or subsequent child, $n=10382$ & 66.7 & 6924 & 33.9 & 3519 & 3.7 & 384 & 0.4 & 40 \\
\hline \multicolumn{9}{|l|}{ Number of cigarettes smoked by mother per day } \\
\hline Non-smoker, $n=12953$ & 76.6 & 9909 & 38.8 & 5025 & 3.9 & 505 & 0.4 & 46 \\
\hline$<10, n=2026$ & 63.8 & 1292 & 26.0 & 526 & 1.9 & 38 & 0.2 & 5 \\
\hline $10-19, n=2211$ & 49.8 & 1101 & 15.9 & 351 & 0.9 & 20 & 0.0 & 0 \\
\hline$\geq 20, n=910$ & 42.9 & 390 & 13.9 & 126 & 1.3 & 12 & 0.2 & 2 \\
\hline \multicolumn{9}{|l|}{ Country of residence } \\
\hline England, $n=14820$ & 72.1 & 10673 & 34.3 & 5088 & 3.2 & 481 & 0.3 & 43 \\
\hline Wales, $n=945$ & 62.8 & 593 & 27.2 & 257 & 2.5 & 24 & 0.2 & 2 \\
\hline Scotland, $n=1716$ & 64.9 & 1111 & 32.6 & 558 & 4.0 & 69 & 0.3 & 6 \\
\hline Northern Ireland, $n=629$ & 51.4 & 323 & 20.3 & 120 & 1.1 & 7 & 0.0 & 0 \\
\hline \multicolumn{9}{|l|}{ NS SEC by mother's occupation } \\
\hline Higher managerial and professional, $n=1307$ & 92.6 & 1210 & 55.1 & 720 & 5.7 & 74 & 0.3 & 4 \\
\hline Lower managerial and professional, $n=4271$ & 84.4 & 3604 & 45.1 & 1926 & 4.4 & 188 & 0.3 & 12 \\
\hline Intermediate, $\mathrm{n}=3288$ & 72.6 & 2385 & 33.9 & 1114 & 2.8 & 91 & 0.3 & 10 \\
\hline Small employers and self-employed, $n=764$ & 80.2 & 612 & 39.4 & 301 & 5.4 & 41 & 0.5 & 4 \\
\hline Lower supervisory and technical, $n=950$ & 66.1 & 627 & 30.4 & 288 & 1.2 & 11 & 0.0 & 0 \\
\hline Semi-routine, $n=3688$ & 58.8 & 2169 & 23.2 & 855 & 2.0 & 74 & 0.2 & 9 \\
\hline Routine, $n=2403$ & 52.4 & 1260 & 21.2 & 510 & 1.7 & 42 & 0.2 & 6 \\
\hline \multicolumn{9}{|c|}{ Equivilised household income in quintiles of the distribution } \\
\hline Highest, $n=4178$ & 85.8 & 3584 & 47.2 & 1973 & 4.7 & 197 & 0.2 & 8 \\
\hline Second highest, $n=3808$ & 77.7 & 2958 & 38.2 & 1455 & 3.3 & 126 & 0.3 & 12 \\
\hline Middle, $n=2895$ & 66.3 & 1915 & 30.2 & 875 & 2.8 & 82 & 0.4 & 12 \\
\hline Second lowest, $n=2878$ & 59.2 & 1701 & 24.4 & 701 & 2.3 & 66 & 0.3 & 8 \\
\hline Lowest, $n=3021$ & 53.8 & 1618 & 19.8 & 599 & 2.1 & 64 & 0.2 & 7 \\
\hline \multicolumn{9}{|l|}{ Family structure } \\
\hline Two-parent, $n=15240$ & 74.0 & 11280 & 36.1 & 5497 & 3.5 & 534 & 0.3 & 44 \\
\hline One-parent, $n=2858$ & 49.9 & 1413 & 18.6 & 530 & 1.6 & 47 & 0.3 & 8 \\
\hline
\end{tabular}

NS SEC - National Statistics Socio-Economic Classification.

SEC gives an indication of how favourable working conditions are for an individual and is based on a range of markers such as job security, promotion opportunities and level of autonomy. One potential weakness in the study is that data on feeding were collected when infants were 9 months old, and this may have led to some recall bias when recording the timing of infant feeding patterns.

The initiation and maintenance of breast-feeding is determined by a range of clinical, personal, social, cultural and environmental factors ${ }^{13,14}$. To meet the revised Department of Health breast-feeding recommendations will require a radical shift in practice and policy in the National Health Service and across society as a whole ${ }^{7}$. The development of public policies and supportive health services are urgently needed to promote breast-feeding, particularly among lower-income groups. In Sweden, where initiation and duration of breast-feeding is substantially higher than in the UK, multi-faceted interventions have been implemented nationally for the last 20 years $^{15}$. A multi-sector approach is crucial for effective action. Further detailed research is required into the barriers that prevent the initiation and maintenance of breast-feeding, particularly among lower-income mothers.

\section{Acknowledgements}

We wish to acknowledge our colleagues and collaborators who are members of the Millennium Cohort Study team: Mel Bartley, Helen Bedford, Neville Butler, John Bynner, Tim Cole, Shirley Dex, Carol Dezateux, Heather Joshi, Alison Macfarlane, Michael Marmot, Catherine Peckham, Ian Plewis, Chris Power, Ingrid Schoon, Peter Shepherd and Kate Smith. 
Table 3 Odds ratio (OR) and 95\% confidence interval (Cl) for effect of social class (National Statistics Socio-Economic Classification) on initiation and exclusivity of breast-feeding

\begin{tabular}{|c|c|c|c|c|}
\hline & \multicolumn{2}{|c|}{ Unadjusted } & \multicolumn{2}{|c|}{$\begin{array}{l}\text { Adjusted for sex of baby, mother's } \\
\text { age and parity, cigarette smoking, } \\
\text { family structure and income }\end{array}$} \\
\hline & OR & $95 \% \mathrm{Cl}$ & OR & $95 \% \mathrm{Cl}$ \\
\hline \multicolumn{5}{|l|}{ Initiated breast-feeding } \\
\hline Higher managerial and professional & - & & - & \\
\hline Lower managerial and professional & 0.43 & $0.33-0.53$ & 0.56 & $0.43-0.67$ \\
\hline Intermediate & 0.21 & $0.17-0.27$ & 0.33 & $0.27-0.43$ \\
\hline Small employers and self-employed & 0.33 & $0.26-0.45$ & 0.56 & $0.40-0.71$ \\
\hline Lower supervisory and technical & 0.16 & $0.12-0.20$ & 0.32 & $0.25-0.42$ \\
\hline Semi-routine & 0.11 & $0.09-0.14$ & 0.26 & $0.21-0.33$ \\
\hline Routine & 0.09 & $0.07-0.11$ & 0.22 & $0.18-0.29$ \\
\hline \multicolumn{5}{|l|}{ Exclusive breast-feeding at 1 month } \\
\hline Higher managerial and professional & - & & - & \\
\hline Lower managerial and professional & 0.67 & $0.59-0.77$ & 0.77 & $0.67-0.91$ \\
\hline Intermediate & 0.42 & $0.36-0.48$ & 0.56 & $0.48-0.67$ \\
\hline Small employers and self-employed & 0.56 & $0.48-0.67$ & 0.71 & $0.59-0.83$ \\
\hline Lower supervisory and technical & 0.36 & $0.30-0.43$ & 0.63 & $0.50-0.71$ \\
\hline Semi-routine & 0.24 & $0.21-0.28$ & 0.43 & $0.38-0.53$ \\
\hline Routine & 0.21 & $0.18-0.24$ & 0.42 & $0.36-0.50$ \\
\hline \multicolumn{5}{|l|}{ Exclusive breast-feeding at 4 months } \\
\hline Higher managerial and professional & - & & - & \\
\hline Lower managerial and professional & 0.71 & $0.56-1.00$ & 0.83 & $0.63-1.11$ \\
\hline Intermediate & 0.45 & $0.33-0.63$ & 0.63 & $0.43-0.83$ \\
\hline Small employers and self-employed & 1.11 & $0.71-1.67$ & 1.25 & $0.83-2.00$ \\
\hline Lower supervisory and technical & 0.20 & $0.10-0.38$ & 0.30 & $0.16-0.59$ \\
\hline Semi-routine & 0.31 & $0.23-0.45$ & 0.53 & $0.36-0.77$ \\
\hline Routine & 0.27 & $0.18-0.40$ & 0.50 & $0.31-0.77$ \\
\hline
\end{tabular}

\section{References}

1 British Paediatric Association. Statement of the standing committee on nutrition. Is breastfeeding beneficial in the UK? Archives of Disease in Childhood 1994; 71: 376-80.

2 Howie PW, Forsyth JS, Ogston SA, Clark A, Florey CD. Protective effect of breast feeding against infection. British Medical Journal 1990; 300: 11-6.

3 Kramer MS, Chalmers B, Hodnett ED, Sevkovskaya Z, Dzikovich I, Shapiro S, et al. Promotion of Breastfeeding Intervention Trial (PROBIT): a randomized trial in the Republic of Belarus. Journal of the American Medical Association 2001; 285: 413-20.

4 Wilson AC, Forsyth JS, Greene SA, Irvine L, Hau C, Howie PW. Relation of infant diet to childhood health: seven year follow up of cohort of children in Dundee infant feeding study. British Medical Journal 1998; 316: 21-5.

5 Collaborative Group on Hormonal Factors in Breast Cancer. Breast cancer and breastfeeding: collaborative reanalysis of individual data from 47 epidemiological studies in 30 countries, including 50302 women with breast cancer and 96973 women without the disease. Lancet 2002; 360: 187-95.

6 Gwinn ML, Lee NC, Rhodes PH, Layde PM, Rubin GL. Pregnancy, breast feeding, and oral contraceptives and the risk of epithelial ovarian cancer. Journal of Clinical Epidemiology 1990; 43: 559-68.

7 World Health Organization (WHO) Secretariat. Infant and young child nutrition; global strategy on infant and young child feeding. Resolution WHA55/15. Geneva: WHO, 2002. Available at http://www.who.int/gb/EB_WHA/PDF/ WHA55/ea5515.pdf. Accessed 25 September 2003.

8 Department of Health. Reducing Health Inequalities: An Action Report. Our Healthier Nation. London: Stationery Office, 1999

9 Department of Health. Improvement, Expansion and Reform: The Next 3 Years. Priorities and Planning Framework 2003-2006. London: Stationery Office, 2002.

10 Hamlyn B, Brooker S, Oleinikova K, Wands S. Infant Feeding 2000. London: Stationery Office, 2002.

11 Dex S, Joshi H, ed. Millenium Cohort Study: First Survey: A User's Guide to Initial Findings. London: Centre for Longitudinal Studies, University of London, 2004.

12 Coxon APM, Fisher K. Criterion Validation and Occupational Classification: The Seven Economic Relations and the NS SEC. Mimeograph. Colchester: Institute for Economic and Social Research, University of Essex, 1999.

13 Maclean HM. Implications of a health promotion framework for research on breast feeding. Health Promotion International 1989; 3: 355-60.

14 Hoddinott P, Pill R. Qualitative study of decisions about infant feeding among women in east end of London. British Medical Journal 1999; 318: 30-4.

15 Protheroe L, Dyson L, Renfrew M, Bull J, Mulvihill C. The Effectiveness of Public Health Interventions to Promote the Initiation of Breastfeeding. London: Health Development Agency, 2003. 